\title{
Concept and Evolution of PLM
}

\author{
Jaykumar Yoga Mule \\ Assistant Professor \\ Department of Mechanical Engineering \\ Maharashtra Institute of Technology, Aurangabad
}

\begin{abstract}
In today's Product lifecycle management is becoming more important as companies compete in the worldwide market because growing product complexity, large number of product variants and collaborative product development has made Product lifecycle Management increasing important for automotive industry, aerospace industries and manufacturing industries. PLM is a collaborative tool enables people throughout extended enterprises to work together more effectively helps organization achieve its business goals of reducing costs, increase revenues, improving product quality, and shortening time to market, increase the value of the product portfolio, and maximize the value of current and future products for both customers and shareholders, increase customer satisfaction, while innovating its products, services, and business operations. The PLM must be implemented in industries for produce excellent product and manage product and its lifecycle throughout. This paper reviews the basic fundamental and Software of PLM and presents PLM support to company as an effective and beneficial tool.
\end{abstract}

\section{Keywords}

PLM Phases, Evolution of PLM, PLM fundamental in automotive sector, PLM Architecture, PLM Scope.

\section{INTRODUCTION}

Product lifecycle management (PLM) is defined as a concept to integrate people, date, processes, tools and business systems and manage product related information throughout the entire product lifecycle [1,2] such that the right information in the right context at the right time can be made available [3]PLM enables the collaborative creation, management, dissemination, and use of product definition and process operation information across the extended enterprise from market concept through design \& manufacturing to service and product retirement. PLM is a collaborative tool enables people throughout extended enterprises to work together more effectively helps organization achieve its business goals of reducing costs, increase revenues, improving product quality, and shortening time to market, increase the value of the product portfolio, and maximize the value of current and future products for both customers and shareholders, increase customer satisfaction, while innovating its products, services, and business operations. The PLM must be implemented in industries for produce excellent product and manage product related information throughout the entire lifecycle of product .In this paper discuss The fundamental of PLM in Automotive industries this vision is enabled by recent advances on information and communication technologies and is needed to support current industry needs for faster innovation cycles combined with effective time \& reduces costs by taking advantage of the efficiencies and effectiveness that come from improved market intelligence and business collaboration.

\section{PLM PHASES}

Product lifecycle management is the process of managing the entire lifecycle of a product from its conception, through design and manufacture, to service and disposal. All products and services have certain life cycles. The life cycle of the product refers to the period from the beginning of life to the end of life and its split up into five major steps in a product's lifecycle. The product's life cycle period usually consists of five major steps or phases Imagine, Define, Realize, Use/Support, and finally Retire/Dispose as shown in figure 1.

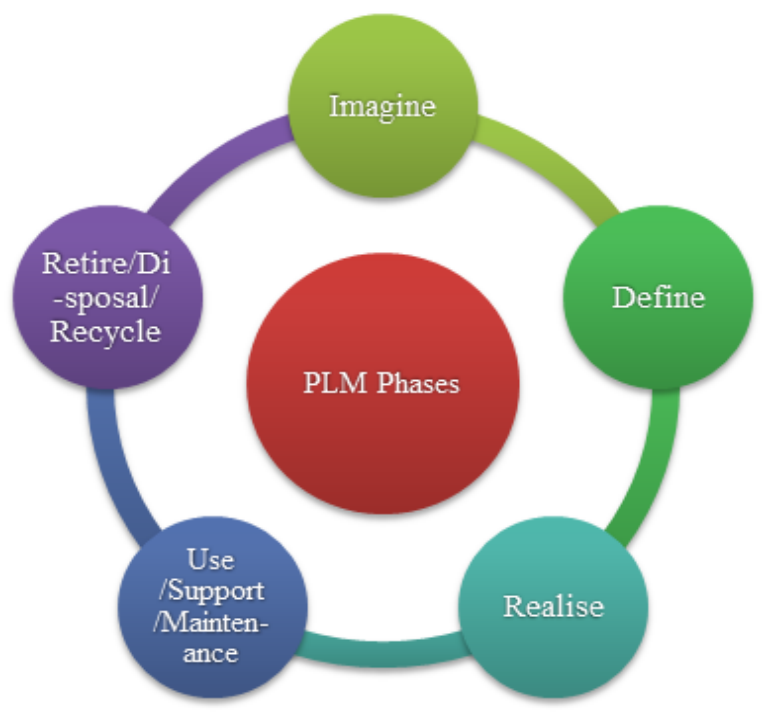

Fig: 1 PLM Phases [4]

In each of the five phases the product is in a different phase and is associated with changes in the marketing situation. During the imagination phase, the product is just an idea in people's mind. This idea may feasible or not feasible but during the definition phase this idea is being converted into a detailed design. By the end of the realization phase the idea converted into physical product, this final product now ready to use by customer. During the use/support phase, the product is with the customer who is using it. Eventually the product gets to a phase in which product is no longer useful and retired by the company, and product disposed by the customer. The product must be managed in all these phases to make sure that everything works well, and that the product makes good money for the company that means managing the product throughout its lifecycle [4] 


\section{EVOLUTION OF PLM}

CAD software enabled the designer to creation of a geometric model of the product more easily in the computer such design can be more easily reused and manipulated by the designer as needed.. The volume of product information created by Computer-Aided Design, Computer-Aided Manufacturing and Computer-Aided Engineering threatened to get out of control [4]. PDM (Product Data Management) appeared in the late 1980 s to support the management and growing volumes of design files generated by CAD (Computer Aided Design) systems. PDM allowed them to standardize items, to store and control document files, to maintain BOM's, to control item, $\mathrm{BOM}$ and document revision levels, and immediately to see relationships between parts and assemblies. This functionality let them quickly access standard items, BOM structures, and files for reuse and derivation, while reducing the risk of using incorrect design versions and increasing the reuse of existing product information [5]. The concept of Product Lifecycle Management (PLM) appeared at the end of the 1990's with the aim of moving beyond engineering aspects of an enterprise product and providing a shared platform for the creation, organization and dissemination of product related information across the extended enterprise. PLM seeks to manage information throughout all the stages of a product's lifecycle such as Imagine, define, realize, use/support, and finally retire/dispose as such; ERP, CRM and SCM are integral parts of PLM [7, 6].

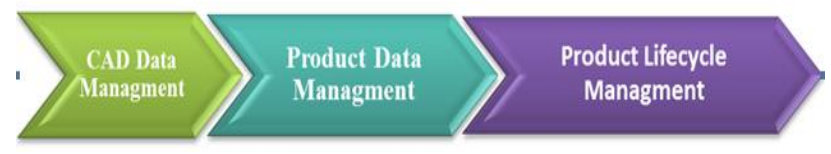

Fig 2: Evolution of PLM

\section{PLM FUNDAMENTAL IN AUTOMOTIVE SECTOR}

Generic PLM applications are those that are applicable to all sectors, all types of products, and all types of user within those companies [8].

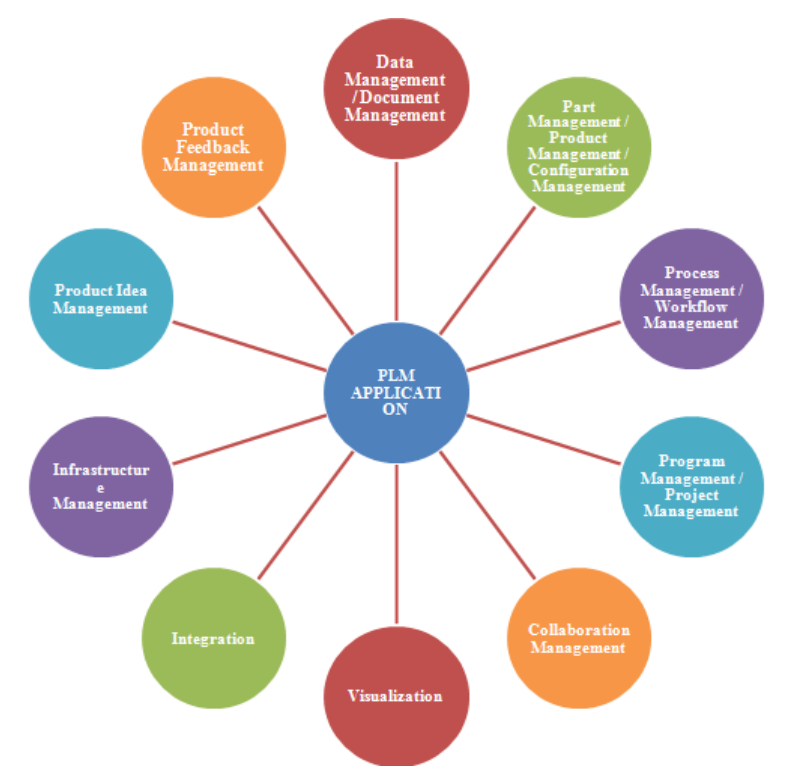

Fig3: Genric PLM Application
$>$ Data Management/Document Management Enable organization to store and make available data (documents/ drawings/files) throughout the entire product lifecycle in a controlled-access secure distributed environment. They enable activities such as version management, revision control, classification, search, analysis and reporting.

\section{$>$ Part/Product..Management/Configuration Management}

Enable organization to manage products, product structures and product attributes and also enable improved design, part and module reuse. Enable activities such as version management, revision control, classification, search, analysis and reporting.

\section{$>$ Process Management/ Workflow Management} Enable organization to map business processes, to define and automate simple workflows (such as change approval and release workflows, and the change management workflow) Templates enable common, repeatable processes. Workflow management includes routing templates, paths, lists, logic and rules. It can include notification management.

\section{> Program Management/ Project Management}

Enable organization to plan, manage and control projects and programs. They enable stage, gate, milestone, and deliverable control. They provide visibility into a project's status in terms of progress and costs. They show interdependencies such as those among project resources and intermediate deliverables. These applications provide a range of display options such as dashboards, cockpit charts, pie charts and graphs.

\section{$>$ Collaboration Management}

These applications enable geographically-dispersed teams and individuals to work together in a secure, structured, virtual working environment using up-to-date product information. They offer a wide range of functionality

\section{$>$ Visualization}

These applications provide viewing, visualization and virtual mock-up capabilities.

\section{$>$ Integration}

These applications enable exchange of product information between PLM applications such as CAD, ERP, SAP and CRM

\section{$>$ Infrastructure Management}

These applications manage services of infrastructure such as networks, databases, and servers.

\section{Idea Management}

These applications enable product ideas to be captured and analyzed, appropriate actions to be initiated, and progress to be tracked.

\section{$>$ Product Feedback Management}

These applications enable feedback about the product to be captured, analyzed and made available where needed

\section{Change management}

$\mathrm{CM}$ a tool with which the latest valid information about changes, such as version changes to a product or component, are recorded in documents or items, which are then made available in the right place and at the right time. [5] 


\section{$>$ Information retrieval}

PLM systems intensify and facilitate the retrieval of information all the existing information on a given subject, such as a particular product, documents, components, can be easily accessed [5]

\section{$>$ File vault.}

It is the place where files the actual data or file attachments are recorded or store. The file vault is usually located near the group of persons who create, update and administer the files. The vault is a file server on the same LAN. The files on the PLM system file server are managed by the system so that correct and controlled revision principle, user privileges and information maintenance are maintained.[5]

\section{PLM ARCHITECTURE}

PLM consists of two main elements, namely a Relational Database Management System (RDBMS) and a File System. The RDBMS typically manages artifact attributes while the file system manages product artifacts. A diagram showing how metadata and artifacts are stored in a PLM data server is shown in the figure below. There are two main computing components to a PLM system a data server and the PLM clients. The data server is the computer system that controls the File Server and the RDBMS. A data server may exist over several locations or may be a combination of servers. The PLM clients are the individual workstations which access the information on the data server. A diagram showing how metadata and artifacts are stored and accessed in PLM ClientServer architecture is shown in the figure below [9]

\section{PLM Clients}

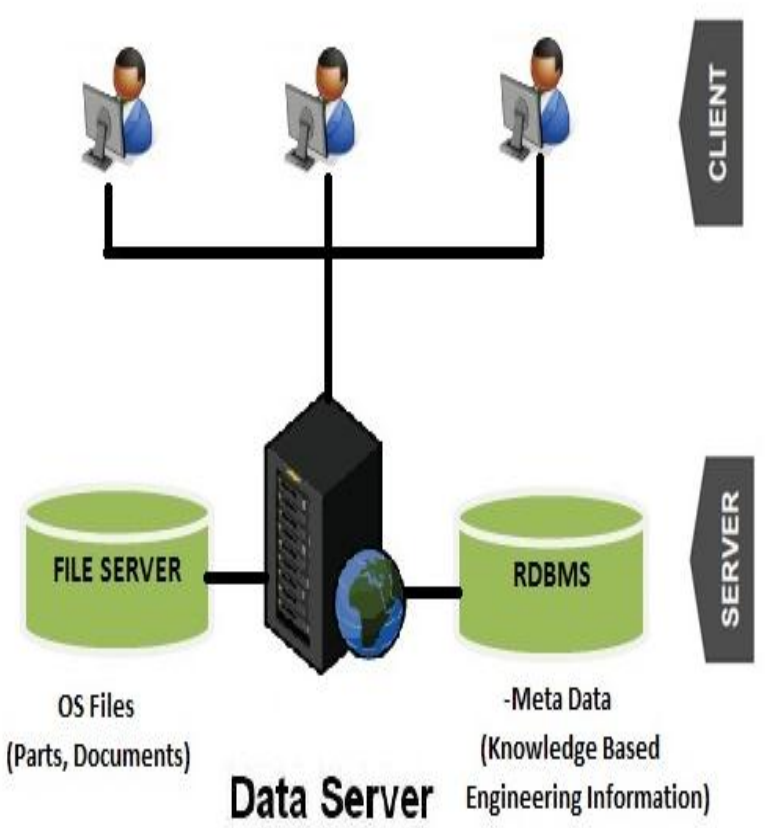

Fig:4 Client sever architecture of PLM [9]

\section{PLM SCOPE IN DIFFERENT SECTORE}

PLM use is beginning to expand beyond engineering to other sectors such as the small industries, medium industries \& large industries (Engineering, business, medical) telecoms, utilities and pharmaceutical sectors. It is expected therefore that new PLM solutions will appear for new business sectors and subsets of these sectors, Companies achieving great success with PLM Software are focused in the following industries [10]

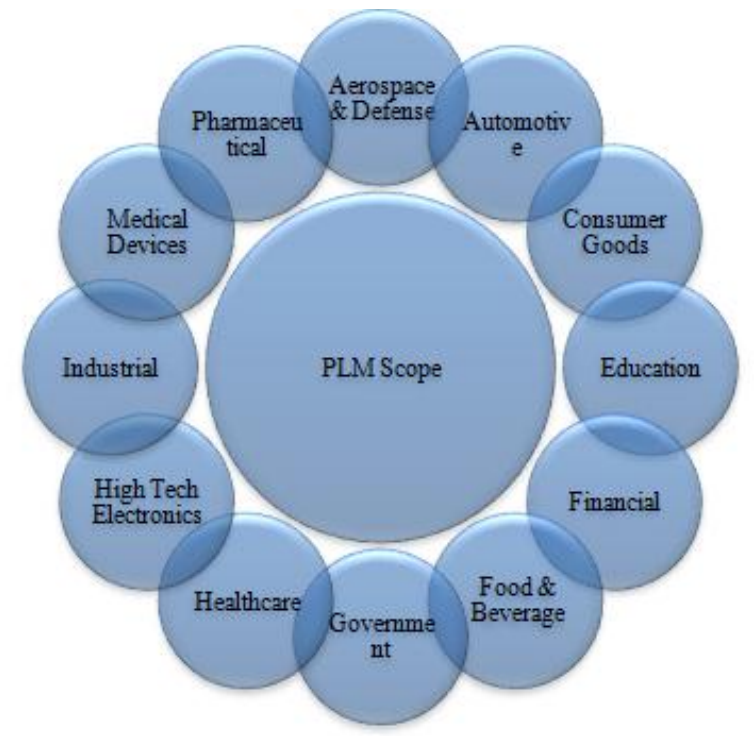

Fig: 5 Scopes for PLM

\subsection{Benefits of PLM}

In today's challenging global engineering market \& people are searching for a way to utilize computing technologies to solve complex problems in industry. The concept of PLM attempts to resolve these issues of added complexity by reducing wasted information, resources, and materials. The PLM system support the product development process and integrating people, process, data, tool, and business systems and providing information for companies and their extended enterprise [11]. The benefits of PLM have been mentioned in recent research and are outlined in the list below. [12]

\footnotetext{
* Reduced time to market

* Improved product quality

* Improved cycle times

* Reduced prototyping costs

* Less scrap \& rework

* Savings through the re-use of original data

* Decreased cost of new product introduction

- A framework for product optimization

* Improved design review and approval processes

* Improved integration and communication with extended supply

* Reduced waste

* Improved communication

* Savings via integration of engineering workflows

* Standards and regulatory compliance
} 


\section{CONCLUSION}

This paper discussed the potential benefits of PLM to reduce the complexity of the product development environment and enable companies to put more of their resources into developing and delivering products and manages products from the beginning of their life, including development, through growth and maturity, to the end of life. Architectures, such as that of PLM offer companies an opportunity to establish a more flexible, comprehensive PLM environment while reducing product-related costs, maintenance, increase product revenues, maximize the value of the product portfolio, and maximize the value of current and future products for both customers and shareholders.

\section{REFERENCES}

[1] Gunther Schuh, Henrique Rozenfeld, Dirk Assmus , Eduardo Zancul, by Process oriented framework to support PLM implementation, Science Direct, Computers in Industry 59 (2008) 210-218, Available online 21 August 2007

[2] S.G. Lee, Y.S. Ma, G.L. Thimm, J. Verstraeten, Product lifecycle management in aviation maintenance, repair and overhaul, Science Direct, Computers in Industry 59 (2008) 296-303, Available online 15 August 2007.

[3] Farhad Ameri1 and Deba Dutta2 (2005), "Product Lifecycle Management: Closing the Knowledge Loops" The University of Michigan, Ann Arbor, ComputerAided Design \& Applications, Vol. 2, No. 5, pp 577-590
[4] John Stark "Product Lifecycle Management" 21st Century Paradigm for Product Realization Second Edition, springer

[5] Antti saaksvuori. Anselmi Immonen, Product Lifecycle Management books second edition, Springer

[6] Piero Lunghi, Marco Botarelli, Michele Ginocchietti, "An innovative framework based on PLM, , RFId \& XML Technology for promoting innovation"POMS 18th Annual Conference Dallas, Texas, U.S.A. May 4 to May 7, 2007

[7] S.G. Lee, Y.S. Ma, G.L. Thimm, J. Verstraeten, Product lifecycle management in aviation maintenance, repair and overhaul, Science Direct, Computers in Industry 59 (2008) 296-303, Available online 15 August 2007.

[8] John Stark "Product Lifecycle Management" 21st Century Paradigm for Product Realization Second Edition, springer

[9] Xu, X. William, Liu, Tony (2003), "A Web-Enabled PDM System in a Collaborative Design Environment", Robotics and Computer-Integrated Manufacturing, vol. 19 , pp.315-328

[10] Understanding Product Lifecycle Management, Datamation Limited, 2002

[11] Grieves, Michael, Product Lifecycle Management, (2006), McGraw Hill

[12] Hill, Sidney. A winning strategy Manufacturing Business Technology, (2006) 